\title{
A Visão Epistemológica De Feyerabend E Suas Possíveis Relações \\ Com A Tendência Metodológica Da Etnomatemática
}

\section{The Epistemological View Of Feyerabend And His Possible Relations With The Methodological Tendency Of Ethnomathematics}

\author{
Clodogil Fabiano Ribeiro dos Santos ${ }^{1}$ \\ Universidade Estadual do Centro-Oeste (Unicentro) - Campus Irati (PR) \\ Nilcéia Aparecida Maciel Pinheiro ${ }^{2}$ \\ Universidade Tecnológica Federal do Paraná (UTFPR) - Campus Ponta Grossa (PR) \\ Programa de Pós-Graduação em Ensino de Ciência e Tecnologia (PPGECT) \\ Edson Jacinski ${ }^{3}$ \\ Universidade Tecnológica Federal do Paraná (UTFPR) - Campus Ponta Grossa (PR) \\ Jussara Rodrigues Ciappina ${ }^{4}$ \\ Universidade Tecnológica Federal do Paraná (UTFPR) - Campus Ponta Grossa (PR)
}

\begin{abstract}
Resumo
O trabalho teve como principal objetivo estabelecer uma relação entre o pluralismo metodológico de Paul Feyerabend e a Etnomatemática, apontando algumas implicações para o ensino de matemática, em especial na Educação Básica, e na aprendizagem de conceitos matemáticos. A pesquisa foi realizada junto a comunidades de imigrantes e descendentes de ucranianos localizadas na Região Centro-Sul do Estado do Paraná, especificamente no que se refere a formas que tais indivíduos efetuam a leitura de relógios. Os resultados obtidos apontam para formas próprias de expressão que podem ser relacionadas a conhecimentos etnomatemáticos característicos desse grupo social. Essas formas de expressão denotam uma identidade cultural que deve ser levada em conta no processo de ensino de conceitos matemáticos, visando estabelecer um diálogo entre a matemática formal e as construções características dessa cultura.
\end{abstract}

Palavras-chave: Pluralismo metodológico; Etnomatemática; Ensino

1 Doutorando em Ensino de Ciência e Tecnologia (PPGECT) pela Universidade Tecnológica Federal do Paraná (UTFPR). Professor de Ensino Superior na Universidade Estadual do Centro-Oeste - Unicentro, Campus de Irati, Paraná, Brasil. E-mail: clodogil@unicentro.br.

2 Doutora em Educação Científica e Tecnológica pela Universidade Federal de Santa Catarina (UFSC). Professora Titular do Departamento Acadêmico de Matemática da Universidade Tecnológica Federal do Paraná (UTFPR) e Docente do Programa de Pós-Graduação em Ensino de Ciência e Tecnologia (PPGECT) da UTFPR, Campus Ponta Grossa, Paraná, Brasil. E-mail: nilceia@utfpr.edu.br.

3 Doutor em Educação Científica e Tecnológica pela Universidade Federal de Santa Catarina (UFSC). Professor Titular do Departamento de Ensino da Universidade Tecnológica Federal do Paraná (UTFPR), Campus Ponta Grossa, Paraná, Brasil. E-mail: ejacinski@utfpr.edu.br.

4 Doutora em em Engenharia Elétrica pela Universidade Estadual de Campinas (Unicamp). Professora do Departamento Acadêmico de Matemática da Universidade Tecnológica Federal do Paraná (UTFPR) e Docente do Programa de Pós-Graduação em Ensino de Ciência e Tecnologia (PPGECT) da UTFPR, Campus Ponta Grossa, Paraná, Brasil. E-mail: jrciappina@utfpr.edu.br. 


\begin{abstract}
The study aimed to establish a relationship between the methodological pluralism of Paul Feyerabend and Ethnomathematics, pointing out some implications for the teaching of mathematics, especially in Basic Education and learning of mathematics concepts. The research was conducted with communities of immigrants and descendants of Ukrainian located in the Center-South region of Paraná, specifically concerns the forms that such individuals carry out the reading of clocks. The results point to forms of expression that may be related to characteristic cultural mathematical knowledges of this social group. These expressions denote a cultural identity that should be taken into account in the mathematical concepts teaching process, to establish a dialogue between the formal mathematical constructions and characteristics of this culture.
\end{abstract}

Keywords: Methodological pluralism; Ethnomathematics; Teaching

\title{
1 Introdução
}

A estruturação da ciência, a descrição do fazer dos cientistas, os problemas que enfrentam em sua atividade profissional, são de interesse da epistemologia. Japiassu afirma que "sabemos muito sobre aquilo que ela não é, e pouco sobre aquilo que é ou se torna" (JAPIASSU, 1934, p.23). Etimologicamente epistemologia é o estudo do conhecimento ou discurso sobre a ciência. Podemos dizer que, na essência, sua principal tarefa é esquadrinhar a ciência e seus atores, visando estabelecer (ou pelo menos tentar) uma espécie de mapa descritivo dessa atividade humana. Dentre esses estudiosos que se auto delegaram essa tarefa está Paul Karl Feyerabend. Sua obra foi um capítulo marcante na história da epistemologia, contrapondo-se a visão monista que permeou a epistemologia do século XX. De acordo com Laburu e Carvalho,

Paul Feyerabend (1924 - 1994), foi um pensador e filósofo austríaco que, indiscutivelmente, tem seu lugar de destaque na epistemologia contemporânea, por defender uma postura epistêmica contrária a tão difundida práxis científica racionalista. Em contrapartida, ele propõe, na sua mais conhecida obra "Contra o Método" [...], o "Anarquismo Epistemológico" que se traduz numa renovada e ousada práxis científica denominada de "Pluralismo Metodológico" (LABURU; CARVALHO, 2001, p. 7).

Neste trabalho propõe-se identificar a implicação do pensamento pluralista para o ensino, em especial da matemática. Especificamente, busca-se identificar possíveis relações com o que alguns autores denominam matemática cultural ou etnomatemática.

A matemática é caracterizada por um alto grau de hermetismo. Tal hermetismo acaba atingindo o seu ensino, pois os encarregados da tarefa de ensinar matemática trazem consigo elementos de uma visão pautada no realismo ingênuo ou no idealismo neoplatônico. A crença mais comum nesse meio é a de que a matemática só pode ser tratada por meio de um processo 
formal, baseado no racionalismo lógico. Nos meios escolares, isso torna a matemática uma espécie de entrave cognitivo. Não conseguindo compreender a linguagem formal característica da matemática escolar, o estudante desiste de tentar entendê-la e relega essa tarefa a supostos privilegiados que conseguem decifrar seus enigmas.

Assim, entende-se que uma metodologia de ensino caracterizada pelo pluralismo de ideias pode ser uma alternativa interessante para romper com essa situação de exclusão cognitiva. Por conta disso, o pensamento de Feyerabend se configura como alicerce teórico para a constituição desse pluralismo metodológico no ensino da matemática. Especificamente, entende-se que a compreensão por parte do professor de que existe uma multiplicidade de interpretações da realidade por diferentes grupos sociais é uma habilidade fundamental para que o processo de ensino de fato ocorra, ou seja, que a intervenção do professor seja eficaz em promover a aprendizagem dos conceitos abordados em suas aulas.

Alguns precedentes relacionados à interveniência de aspectos culturais nas formas de expressão de grandezas e medidas foram identificados em trabalho anterior, no caso específico, métodos de medição de áreas de plantio (HUL et al., 2016). Embora posterior, o estudo se pautou pelo mesmo precedente cultural, mas teve sua análise mais rápida, permitindo que os seus resultados fossem publicados antes. A análise aqui realizada demandou maior aprofundamento, pois o objetivo era estabelecer uma relação com o conceito de pluralismo metodológico.

\section{2. À Guisa De Síntese Do Pensamento De Feyerabend}

Em sua principal obra (FEYERABEND, 1977), o epistemólogo defende a ideia do pluralismo metodológico, opondo-se ao racionalismo, visão epistemológica presente especialmente na obra de Popper e de Lakatos (SILVEIRA, 1996).

O posicionamento mais emblemático de Feyerabend é a sua defesa de um "anarquismo epistemológico", que

... significa, antes, oposição a um princípio único, absoluto, imutável de ordem, do que oposição a toda e qualquer organização. Na sua tradução metodológica, não significa, portanto, ser contra todo e qualquer procedimento metodológico, mas contra a instituição de um conjunto único, fixo, restrito de regras que se pretenda universalmente válido, para toda e qualquer situação [...]. $\mathrm{O}$ anarquista epistemológico não se recusará a examinar qualquer concepção, admitindo que, por trás do mundo tal como descrito pela ciência, possa ocultar-se uma realidade mais profunda, ou que as percepções possam ser dispostas de diferentes maneiras e que a escolha de uma particular disposição correspondente à realidade não será mais racional 
ou objetiva que outra (REGNER, 1996, p. 233-234).

Portanto, Feyerabend (1977) propõe uma alternativa à visão racionalista da ciência, manifestada pelo racionalismo crítico de Popper e, na sua forma mitigada desse, pelo "novo racionalismo" de Lakatos (REGNER, 1996, p. 234). Para o racionalismo, o conhecimento é único, abstrato e baseado no argumento. É aí que reside a crítica de Feyerabend.

A razão criticada por Feyerabend como a faculdade pela qual os padrões de tal tradição se exercem, traduzindo-se em obediência a regras fixas e a padrões imutáveis, estabelecendo e submetendo-se a algo como o método, concentrado, na sua versão contemporânea mais fiel, nas seguintes regras: 1) Só aceitar hipóteses que se ajustem a teorias confirmadas ou corroboradas e 2) Eliminar hipóteses que não se ajustem a fatos bem estabelecidos (REGNER, 1996, p. 235).

Feyerabend relaciona tais regras ao empirismo e ao indutivismo, pois coloca nos fatos observados a função de juiz da verdade. Feyerabend propõe outro caminho: o da contraindução. Nesse aspecto, essa “"contra-regra' [...] aconselha-nos a introduzir e elaborar hipóteses que não se ajustam a teorias firmadas ou a fatos bem estabelecidos. Aconselha-nos a proceder contra-indutivamente" (FEYERABEND, 1977, p. 39). Nas palavras do autor, ao adotar o pluralismo, compete ao cientista

\begin{abstract}
... comparar idéias antes com outras idéias do que com a 'experiência' e ele tentará antes aperfeiçoar que afastar as concepções que forem vencidas no confronto. Procedendo dessa maneira, manterá as teorias acerca do homem e do cosmos que se encontram no Gênese ou no Pimandro e as elaborará e utilizará a fim de avaliar o êxito da evolução e de outras concepções 'modernas'. [...]. O conhecimento, concebido segundo essas linhas, não é uma série de teorias coerentes, a convergir para uma doutrina ideal; não é um gradual aproximar-se da verdade. É, antes, um oceano de alternativas mutuamente incompatíveis (e, talvez, até mesmo incomensuráveis), onde cada teoria singular, cada conto de fadas, cada mito que seja parte do todo força as demais partes a manterem articulação maior, fazendo com que todas concorram, através desse processo de competição, para o desenvolvimento de nossa consciência. (FEYERABEND, 1977, p. 40-41).
\end{abstract}

Nessa concepção, o grau de aceitabilidade de uma determinada cosmovisão, por exemplo, a indígena, é tão importante quanto a cosmovisão baseada na teoria do Big Bang, ou outra cientificamente aceita. Com isso, o cientista ganha maior conteúdo comparativo, podendo escolher o que se poderia considerar o melhor de dois (ou mais) mundos. Contudo, se o discurso científico e as cosmogonias culturalmente construídas têm igual valor lógico, que elementos do primeiro o colocam em situação privilegiada em relação às demais visões de mundo? Mais além, se há, segundo Feyerabend, certa "equivalência" entre o pensamento científico e as construções cosmogônicas baseadas em relatos mitológicos, por que somente a Ciência merece 
status de conhecimento escolar e os outros tipos de conhecimento sejam abordados como meras curiosidades mitológicas?

Esse questionamento deriva do posicionamento relativista de Feyerabend, em contraposição ao discurso permeado pelo realismo crítico e pelo positivismo. Nesse aspecto, pode-se concluir que a atual abordagem utilizada no Ensino de Ciências ainda guarda ligações muito fortes com essas posições que Feyerabend critica.

Apesar da importância dessas questões, o foco da presente discussão é estabelecer uma relação entre o pensamento de Feyerabend e a vertente sociocultural do ensino da matemática, representada pela Etnomatemática. Tal tendência tem ganhado importância, especialmente pelo fato de que é uma das responsáveis por trazer o debate sobre diversidade para a Educação Matemática, temática esta discutida também pela Educação Matemática Crítica.

\section{Breve Discussão Sobre A Etnomatemática}

O termo "Etnomatemática" aparece no que Fiorentini (1995, p. 25) denomina de Tendência Socioetnocultural. Nas palavras do autor,

O grande mérito da etnomatemática foi trazer uma nova visão de matemática e de educação matemática de feição antropológica, social e política, que passam a ser vistas como atividades humanas determinadas socioculturalmente pelo contexto em que são realizadas. A Matemática, por exemplo, só adquire validade e significação no interior de um grupo cultural [...] onde se encontra presente nas diferentes práticas socioculturais (FIORENTINI, 1995, p.25).

Essa vertente tem por principal característica considerar os saberes matemáticos de determinados grupos sociais. Etimologicamente, o termo apresenta em sua constituição o significado mais básico: etno = povo, nação, cultura; matema = explicação, conhecimento; tica = técnica, ideia, procedimento. Assim, etnomatemática seria uma forma própria de cada nicho cultural de resolver problemas, lidar com sua realidade expressar representações através de padrões próprios.

Ao longo da história, outras denominações se ocuparam dessa tarefa. As principais, segundo Rosa e Orey (2005), foram:

- Sociomatemática - Cláudia Zaslavski, 1973;

- Matemática Espontânea - Ubiratan D'Ambrosio, 1982;

- Matemática Informal - Posner, 1982;

- Matemática Oral - Carraher e Schliemann, 1982; 
- Matemática Oprimida - Paulus Gerdes, 1982;

- Matemática Não Estandartizada - Gerdes, Carraher e Harris, 1987;

- Matemática Escondida ou Congelada - Gerdes, 1985;

- Matemática Popular - Mellin-Olsen, 1986;

- Matemática codificada no Saber-Fazer - Eduardo S. Ferreira, 1986.

Qualquer dessas denominações tinha o propósito discutir formas de desvendar a cosmovisão de determinados grupos humanos, objetivando identificar nelas algumas estruturas similares às da matemática formal.

Um trabalho que se assemelha ao que ora é descrito é Knijnik (2003). Nesse trabalho, a autora relata o resgate de formas próprias de expressão e metodologias de plantio. Como a própria autora descreve, "houve o resgate dos modos próprios do grupo em lidar com o cultivo da alface, e, concomitantemente, foram sendo estabelecidas conexões entre os saberes populares e os acadêmicos, que possibilitariam uma acompanhamento mais preciso do processo produtivo" (KNIJNIK, 2003, p.101).

E qual a relação dessa tendência na investigação em Educação Matemática com o pensamento de Feyerabend? Embora não aparentem semelhanças em seus propósitos, pode-se estabelecer essa relação no que se refere à valorização de formas de racionalidade diferentes daquelas que, à primeira vista, parecem caracterizar a ciência. De fato, em cada cosmovisão, há uma estrutura culturalmente construída, com descrições próprias de padrões observados na realidade e que podem ser a porta de entrada para a zona de diálogo entre duas concepções de mundo aparentemente incompatíveis entre si.

Analisando a possibilidade de estabelecimento desse diálogo, D'Ambrosio (2002) considera que a própria matemática é uma forma de etnomatemática. Entende que, ao longo da história, os elementos que foram sendo incorporados a esse corpo de conhecimento foram gestados em determinados grupos culturais, ora agregando elementos míticos, ora desenvolvendo estruturas dotadas de racionalidade intrínseca, do mesmo modo que as elaborações de outros nichos culturais. Assim, defende que não há diferença entre as tradições. Nesse ponto, há uma afirmação de Feyerabend em relação a cosmologias divergentes quando afirma que:

Trata-se, em todos os casos, de pressupostos abstratos e altamente discutíveis que dão forma à nossa concepção do mundo, sem se tornarem acessíveis a uma crítica direta. Em geral, nem sequer nos damos conta desses pressupostos e só lhes reconhecemos os efeitos quando nos defrontamos com uma cosmologia inteiramente diversa: os preconceitos são descobertos graças a contraste e não graças a análise. O material de que o cientista dispõe, inclusive suas mais elaboradas teorias e suas técnicas mais refinadas, estrutura-se de 
modo exatamente idêntico. Encerra, também, princípios que não são conhecidos e que, se conhecidos, seriam de verificação extremamente difícil. (FEYERABEND, 1977, p. 42).

Portanto, considera-se precipitado afirmar que a matemática formal seria a única forma correta e aceitável dessa tradição intelectual, pois pode-se encontrar algum corpo de conhecimentos que não partilha da mesma estrutura axiomática, mas que traz uma estruturação intrinsecamente coerente e ajustada à identidade cultural da sociedade que o produziu. Se a história da matemática for revisitada com esse olhar, será possível perceber tais episódios, o que corrobora a tese de que a matemática é uma forma de etnomatemática.

Há também uma questão política e de subordinação cultural envolvida na visão monista da matemática. Nesse sentido, Knijnik afirma que:

\begin{abstract}
a investigação das tradições, práticas e concepções matemáticas de um grupo social subordinado (quanto ao volume e composição de capital social, cultural e econômico) e o trabalho pedagógico que se desenvolve com o objetivo de que o grupo interprete e decodifique seu conhecimento; adquira o conhecimento produzido pela Matemática acadêmica, estabeleça comparações entre o seu conhecimento e o conhecimento acadêmico, analisando as relações de poder envolvidas no uso destes dois saberes (KNIJNIK apud KNIJNIK, 2003, p.100).
\end{abstract}

A ideia da autora, com a qual estes autores concordam, é que, muitas vezes, a matemática acadêmica e, por extensão, a matemática escolar, figuram como formas de conhecimento supostamente superiores e, muitas vezes, inatingíveis, relegadas a poucos "iniciados". Tal sentimento pode se constituir num dos fatores que impactam negativamente na aprendizagem dos conceitos matemáticos. Superar tal dicotomia a partir do estabelecimento de relações entre os saberes e da adoção de uma visão metodológica de ensino mais pluralista é o grande desafio que se coloca para todo professor de matemática.

\title{
4 Objeto De Pesquisa
}

Considera-se que alguns grupos sociais praticam diferentes "matemáticas", com seus métodos próprios, pautados nas cosmovisões particulares de sua cultura. Assim, como afirma D'Ambrosio, no seio de cada prática social residem conhecimentos matemáticos.

A proposta deste trabalho é identificar algumas práticas que possam ser relacionadas com conceitos matemáticos. Em especial, o grupo a ser investigado é composto de imigrantes e descendentes de ucranianos residentes na região Centro-Sul do Paraná. A partir da compreensão dessas práticas como habilidades etnomatemáticas, considera-se que seria 
possível planejar atividades de ensino com maior potencial de promover aprendizagem.

Dentre as produções culturais desse grupo, destacam-se as artes visuais populares, as formas de contagem, utilização de grandezas e medidas (espaciais, temporais, de quantidade etc.), permeadas em discursos cotidianos. Nos bordados e ovos de Páscoa são frequentes as formas geométricas, a perspectiva, a intenção de tridimensionalidade, ideias sobre o infinito, entre outros aspectos.

No presente trabalho serão abordadas as formas de leitura de horas em relógios, obtidas a partir de entrevistas gravadas em áudio, durante a constituição de dados de uma pesquisa referente às formas próprias de expressão, tanto no idioma característico do grupo cultural, quanto na língua portuguesa. A pesquisa empregou a metodologia das entrevistas sociolinguísticas e foi utilizada no trabalho de composição do acervo linguístico denominado VARLINFE (COSTA; LOREGIAN-PENKAL, 2015). Conforme descrito pelas autoras do estudo, o grupo social definido para a pesquisa teve os seguintes requisitos de escolha:

1. Falantes descendentes de eslavos (ou seja, descendente de ucraniano ou polonês, de pai ou de mãe ou de ambos. Ter nascido na comunidade e/ou ter se mudado para lá no máximo aos 2 anos de idade). 2. Não ter viajado intensamente para outras localidades (por exemplo, o informante não poderia ter sido caminhoneiro ou vendedor); 3. Morar na zona rural de um dos seis municípios incluídos na amostra (COSTA; LOREGIAN-PENKAL, 2015, p.101).

A partir das falas gravadas, foi realizada uma análise descritiva, sem tentar ingressar em tentativas de interpretação, pois estas seriam por demais influenciadas pelo conhecimento matemático do pesquisador. Foi necessário utilizar algumas categorias presentes no pensamento matemático escolar, no sentido de procurar compreender as produções culturais pesquisadas e estabelecer um diálogo com essa instância do saber.

Em princípio, considera-se neste trabalho a existência de uma distinção entre matemática acadêmica e matemática escolar, que segundo Moreira e David (2010), difere-se da matemática acadêmica, especialmente por conta do "eventual afastamento das normas do saber sábio" e de "uma proximidade 'perigosa' em relação ao saber 'banalizado', isto é, de domínio público" (MOREIRA; DAVID, 2010, p. 18). Discordando das ideias de Chevallard, os citados autores defendem que "independentemente do fato de que o saber a ser ensinado provenha ou não de um corpo científico de conhecimentos, o trabalho de ensinar requer a construção de uma percepção peculiar do objeto de ensino" (p. 18). Percebe-se também que os autores criticam a concepção de Chevallard de que, em última instância, a matemática escolar é subsidiária da matemática acadêmica. Dessa maneira, aquele autor seria um crítico de eventuais "desvios em 
relação ao conhecimento matemático científico" (p. 19).

Nessa mesma linha de raciocínio, o trabalho de Vilela e Meneghetti (2011) também figura como balizador, em especial no que se refere à pertinência da discussão sobre a dualidade cardinal - ordinal, que serve de base para analisar os discursos dos sujeitos da pesquisa.

Enfim, é possível conceber que a matemática escolar também pode ser uma forma de etnomatemática, caracterizada pelo vínculo cultural com a realidade a que pertence a escola. Isso permite pensar que numa escola situada em determinada comunidade, caracterizada por uma identidade cultural, presente nas práticas e costumes da sociedade que contém a escola, as formas socialmente compartilhadas de conhecimento têm influência mais acentuada que o saber acadêmico. Portanto, entende-se como válido o esforço de tentar compreender as formas de conhecimento ali praticadas e tentar estabelecer um diálogo com os conteúdos escolares.

\subsection{A Pesquisa}

A obtenção dos dados de pesquisa, como foi revelado anteriormente, foi feita por meio de entrevistas gravadas, durante sessões de entrevistas sociolinguísticas, conduzidas ao longo do ano de 2013, em comunidades de imigrantes e descendentes de ucranianos. O foco da pesquisa foi a forma como os entrevistados faziam a leitura de horas em relógios.

Tendo em vista seguir um viés descritivo, buscou-se identificar nas formas de leitura de horas elementos que evidenciassem determinadas características. Dentre tais elementos, podese destacar a presença de organizações próprias dos grupos culturais pesquisados em comparação com as normas de linguagem entendidas como adequadas para expressar o mesmo conceito.

O idioma ucraniano é caracterizado por uma forma própria de contagem de horas, na qual é possível identificar o imbricamento entre números cardinais e ordinais. Vilela e Meneghetti (2011) abordam essa questão, destacando que, a princípio, não há na matemática acadêmica nenhum indício de distinção entre essas duas características. Entretanto, isso pode ser encontrado na matemática escolar. As autoras assumem que "não há ligações necessárias ou hierárquicas que permitam relações de legitimação entre as práticas matemáticas escolares e acadêmicas, no sentido de uma correspondência entre estes objetos particulares, o número ordinal e cardinal." (VILELA; MENEGHETTI, 2011, p. 180).

Considerando, portanto como válidas as características de cardinalidade e ordinalidade para a análise aqui proposta, tem-se como ponto de partida as construções consideradas formais 
no citado idioma. No quadro 1, são transcritas as formas numéricas das horas, seguidas de sua escrita no idioma original e de sua tradução literal. Destaque-se que a própria forma numérica considerada como correta não segue os padrões considerados adequados para a representação de grandezas de tempo no sistema sexagesimal. Entretanto, não cabe aqui estabelecer balizadores corretivos, visto que o propósito do estudo é identificar as formas culturalmente válidas de conhecimento. Sendo assim, a forma considerada como formalmente adequada no idioma original também apresenta aspectos de identidade cultural própria.

No quadro 2, são apresentadas as formas de expressão dos mesmos códigos numéricos pelos sujeitos da pesquisa. Com vistas a estabelecer um comparativo entre as formas de escrita manifestadas pelos sujeitos da pesquisa, procurou-se alocá-las lado a lado, de forma a permitir uma visualização na íntegra, possibilitando uma análise mais detalhada.

Nas expressões do quadro 1, é possível notar que as horas são lidas utilizando ordinais, enquanto os minutos seguem o conceito de cardinalidade. Apesar de ser uma forma própria de expressão, há uma relação com métodos medir o tempo manifestados por diferentes povos. De acordo com Almeida,

As várias sociedades, especialmente as primitivas, têm diferentes conceitos de tempo e impõem diferentes estruturas no cômputo de seu transcorrer. Ideias matemáticas como ordem, unidades e ciclos, são os tijolos com que essas estruturas são erigidas. $\mathrm{O}$ conceito e a estruturação do tempo, adotados por uma cultura e ensinados aos seus filhos, tornam-se parte tão íntima de sua vida diária que muitas vezes não conseguem atinar que outros povos podem perceber, organizar e medir o tempo de forma diferente (ALMEIDA, 2013, p. 159).

Essas diferenças podem ser percebidas também entre comunidades que, embora originárias de determinado contexto cultural, por conta de mudança do espaço geográfico, acabaram recebendo influência de outra cultura, acarretando algumas modificações na forma original de expressão.

Ainda que preservem elementos da cultura original, é possível perceber fatores que distinguem suas formas de expressão. Este é o caso que é relatado neste estudo, conforme expressões constantes do quadro 2. Note-se que existem algumas diferenças entre as expressões mostradas no citado quadro, o que permite identificar duas situações: (1) existe um "núcleo comum" nas formas de leitura das horas, representado principalmente pela predominância da ordinalidade na expressão das horas, sucedido pela cardinalidade da leitura dos minutos; (2) pode-se perceber uma influência das formas de expressão comumente encontradas na língua portuguesa, fruto da miscigenação cultural. 


\begin{tabular}{|c|c|c|}
\hline $\begin{array}{c}\text { Forma numérica (considerada } \\
\text { correta no idioma original) }\end{array}$ & Escrita no idioma original & Tradução literal da escrita original \\
\hline 18.50 & За десять хвилин сьома. & Em dez minutos sétima (hora). \\
\hline 15.30 & $\begin{array}{c}\text { Половина четвертої. Пів на } \\
\text { четверту. }\end{array}$ & $\begin{array}{c}\text { Metade da quarta. Meio da quarta } \\
\text { (hora). }\end{array}$ \\
\hline 12.55 & За п'ять хвилин перша. & Em cinco minutos primeira (hora). \\
\hline 19.00 & Сьома година. & Sétima hora. \\
\hline 21.20 & Двадцять хвилин на десяту. & Vinte minutos da décima (hora). \\
\hline 23.05 & П'ять хвилин на дванадцяту. & $\begin{array}{c}\text { Cinco minutos da décima segunda } \\
\text { (hora). }\end{array}$ \\
\hline 14.45 & За чверть трета. & Em um quarto (de hora) terceira (hora). \\
\hline 13.15 & Чверть на другу. & Quarto (de hora) da segunda (hora). \\
\hline
\end{tabular}

Quadro 1: Formas numéricas de representação de horas, seguidas de sua forma escrita por extenso, primeiro no idioma original e, em seguida, em sua forma literalmente traduzida

Fonte: acervo de dados dos autores

\begin{tabular}{|c|c|c|c|c|c|c|}
\hline \multirow{2}{*}{$\begin{array}{l}\text { Forma } \\
\text { numérica } \\
\text { (correta no } \\
\text { idioma } \\
\text { original) }\end{array}$} & \multicolumn{2}{|c|}{ Sujeito 1} & \multicolumn{2}{|c|}{ Sujeito 2} & \multicolumn{2}{|c|}{ Sujeito 3} \\
\hline & $\begin{array}{c}\text { Escrita no } \\
\text { idioma original }\end{array}$ & $\begin{array}{l}\text { Tradução } \\
\text { literal da } \\
\text { expressão } \\
\text { original }\end{array}$ & $\begin{array}{c}\text { Escrita no } \\
\text { idioma original }\end{array}$ & $\begin{array}{l}\text { Tradução } \\
\text { literal da } \\
\text { expressão } \\
\text { original }\end{array}$ & $\begin{array}{l}\text { Escrita no } \\
\text { idioma } \\
\text { original }\end{array}$ & $\begin{array}{l}\text { Tradução } \\
\text { literal da } \\
\text { expressão } \\
\text { original }\end{array}$ \\
\hline 18.50 & $\begin{array}{c}\text { Вісімнайцята } \\
\text { година й } \\
\text { п'ятдесять } \\
\text { хвилин. } \\
\end{array}$ & $\begin{array}{c}\text { Décima oitava } \\
\text { hora e } \\
\text { cinquenta } \\
\text { minutos. }\end{array}$ & $\begin{array}{c}\text { Десять хвилин } \\
\text { до } \\
\text { дев'ятнадцятої } \\
\text { години. }\end{array}$ & $\begin{array}{l}\text { Dez minutos } \\
\text { para a } \\
\text { décima nona } \\
\text { hora. }\end{array}$ & $\begin{array}{c}\text { Вісімнадцята } \\
\text { година й } \\
\text { п'ятдесять } \\
\text { хвилин. } \\
\end{array}$ & $\begin{array}{l}\text { Décima } \\
\text { oitava hora e } \\
\text { cinquenta } \\
\text { minutos. }\end{array}$ \\
\hline 12.55 & $\begin{array}{c}\text { Дванатьцята } \\
\text { година й } \\
\text { п'ятдесять } \\
\text { п'ять хвилин. }\end{array}$ & $\begin{array}{c}\text { Décima } \\
\text { segunda hora } \\
\text { e cinquenta e } \\
\text { cinco minutos. }\end{array}$ & $\begin{array}{c}\text { П'ять до } \\
\text { тринадцятої } \\
\text { години. }\end{array}$ & $\begin{array}{l}\text { Cinco para a } \\
\text { décima } \\
\text { terceira hora. }\end{array}$ & $\begin{array}{c}\text { Дванадцята } \\
\text { година й } \\
\text { п'ятдесять } \\
\text { п'ять хвилин. }\end{array}$ & $\begin{array}{c}\text { Décima } \\
\text { segunda hora } \\
\text { e cinquenta e } \\
\text { cinco } \\
\text { minutos. }\end{array}$ \\
\hline 19.00 & $\begin{array}{c}\text { Девятнайцята } \\
\text { година. }\end{array}$ & $\begin{array}{l}\text { Décima nona } \\
\text { hora. }\end{array}$ & $\begin{array}{c}\text { Дев'ятнадцята } \\
\text { година. }\end{array}$ & $\begin{array}{l}\text { Décima nona } \\
\text { hora. }\end{array}$ & $\begin{array}{c}\text { Дев'ятнадцята } \\
\text { година. }\end{array}$ & $\begin{array}{l}\text { Décima nona } \\
\text { hora. }\end{array}$ \\
\hline 21.20 & $\begin{array}{l}\text { Двайцята } \\
\text { (перша) } \\
\text { година й } \\
\text { двайцять } \\
\text { хвилин. }\end{array}$ & $\begin{array}{l}\text { Vigésima } \\
\text { (primeira) } \\
\text { hora e vinte } \\
\text { minutos. }\end{array}$ & $\begin{array}{c}\text { Двадцять-перша } \\
\text { година й } \\
\text { двадцять } \\
\text { хвилин. }\end{array}$ & $\begin{array}{l}\text { Vigésima } \\
\text { primeira } \\
\text { hora e vinte } \\
\text { minutos. }\end{array}$ & $\begin{array}{c}\text { Двадцять } \\
\text { одна година й } \\
\text { двадцять } \\
\text { хвилин. }\end{array}$ & $\begin{array}{l}\text { Vinte e uma } \\
\text { hora e vinte } \\
\text { minutos. }\end{array}$ \\
\hline 23.05 & $\begin{array}{c}\text { Двайцята трета } \\
\text { година й пять } \\
\text { хвилин. } \\
\end{array}$ & $\begin{array}{c}\text { Vigésima } \\
\text { terceira hora e } \\
\text { cinco minutos. }\end{array}$ & $\begin{array}{c}\text { П'ять хвилин до } \\
\text { півночі. }\end{array}$ & $\begin{array}{c}\text { Cinco } \\
\text { minutos para } \\
\text { a meia noite. }\end{array}$ & $\begin{array}{c}\text { Двадцять й } \\
\text { три години й } \\
\text { пять хвилин. }\end{array}$ & $\begin{array}{l}\text { Vinte e trés } \\
\text { horas e cinco } \\
\text { minutos. }\end{array}$ \\
\hline 14.45 & $\begin{array}{c}\text { Чотернайцята } \\
\text { година й сорок } \\
\text { пять хвилин. }\end{array}$ & $\begin{array}{c}\text { Décima quarta } \\
\text { hora e } \\
\text { quarenta e } \\
\text { cinco minutos. }\end{array}$ & $\begin{array}{l}\text { Чотирнадцята } \\
\text { година, сорок } \\
\text { п'ять хвилин. }\end{array}$ & $\begin{array}{l}\text { Décima } \\
\text { quarta hora, } \\
\text { quarenta e } \\
\text { cinco } \\
\text { minutos. }\end{array}$ & $\begin{array}{c}\text { Чотирнадцята } \\
\text { година й } \\
\text { сорок пять } \\
\text { хвилин. }\end{array}$ & $\begin{array}{l}\text { Décima } \\
\text { quarta hora e } \\
\text { quarenta e } \\
\text { cinco } \\
\text { minutos. }\end{array}$ \\
\hline 13.15 & $\begin{array}{c}\text { Тринатьцята } \\
\text { година й } \\
\text { пятнайцят } \\
\text { хвилин. }\end{array}$ & $\begin{array}{l}\text { Décima } \\
\text { terceira hora e } \\
\text { quinze } \\
\text { minutos. }\end{array}$ & $\begin{array}{c}\text { Тринадцята } \\
\text { година, } \\
\text { п'ятнадцять } \\
\text { хвилин. }\end{array}$ & $\begin{array}{l}\text { Décima } \\
\text { terceira hora, } \\
\text { quinze } \\
\text { minutos. }\end{array}$ & $\begin{array}{c}\text { Тринадцята } \\
\text { година й } \\
\text { пяднацят } \\
\text { хвилин. }\end{array}$ & $\begin{array}{l}\text { Décima } \\
\text { terceira hora } \\
\text { e quinze } \\
\text { minutos. }\end{array}$ \\
\hline
\end{tabular}




\begin{tabular}{|c|c|c|c|c|c|c|}
\hline 15.30 & $\begin{array}{c}\text { Пятнайцята } \\
\text { година й } \\
\text { тридцять } \\
\text { хвилин. }\end{array}$ & $\begin{array}{l}\text { Décima quinta } \\
\text { hora e trinta } \\
\text { minutos. }\end{array}$ & $\begin{array}{c}\text { Тридцять } \\
\text { хвилин до } \\
\text { шістнадцятої } \\
\text { години. }\end{array}$ & $\begin{array}{c}\text { Trinta } \\
\text { minutos para } \\
\text { a décima } \\
\text { sexta hora. }\end{array}$ & $\begin{array}{c}\text { Пяднацята } \\
\text { година й } \\
\text { тридцять } \\
\text { хвилин. }\end{array}$ & $\begin{array}{c}\text { Décima } \\
\text { quinta hora e } \\
\text { trinta } \\
\text { minutos. }\end{array}$ \\
\hline
\end{tabular}

Quadro 2: Formas de expressão escrita da leitura da horas pelos sujeitos da pesquisa, estudantes de graduação em matemática que possuem algum conhecimento do idioma ucraniano

Fonte: acervo de dados dos autores

A precedência da ordinalidade na leitura das horas, enquanto unidade de tempo resultante da divisão do dia, figura como um indício da precedência histórica da comparação em relação à contagem. Em relação a esse aspecto, Almeida relata que

Talvez uma das primeiras noções matemáticas as ser empregada pela humanidade relaciona-se à noção de ordem, de ordenação, fundamental para o estabelecimento de classificações. Implica no reconhecimento de classes de objetos: objetos curtos ou compridos, leves ou pesados, de pedra ou de madeira, de pele ou de chifre, redondos ou lineares, e assim por diante. Perante uma diversidade de objetos, a noção de ordem permite ao homem primitivo dividi-los em classes, estabelecendo assim uma taxonomia: objetos de pedra, de madeira, armas, ferramentas etc. A noção de classificação é anterior, portanto, à contagem (ALMEIDA, 2013, p. 178).

Isso poderia explicar o fato de que as horas, conceito precedente na mensuração do tempo, utilize a numeração ordinal, enquanto os minutos, conceito posterior, resultante da divisão da hora, sigam o critério cardinal. Entretanto, a observação do conteúdo do quadro 2 evidencia alguma influência do sistema ocidental de leitura de horas, caracterizado pela cardinalidade.

\subsection{Análise Dos Dados À Luz Da Epistemologia De Feyerabend}

Pode-se observar em relação aos dados obtidos e às formas consideradas adequadas que o conhecimento socialmente construído pelo grupo étnico pesquisado é dotado de uma estrutura bem elaborada. Sobre esse aspecto, Feyerabend é contrário à instituição de um único e imutável sistema de regras para a compreensão do mundo. Segundo Laburu et al.,

Na sua tradução em estratagemas de ensino ele não revela, portanto, ser contra todo e qualquer procedimento metodológico, mas contra a instituição de um conjunto único, frio, restrito, de regras que se pretenda serem universalmente aceitas e principalmente válidas e verdadeiras para qualquer e toda situação de aluno, professor, sala de aula, faixa etária, escola, etnia cultural, lingüística, matéria, conceito, etc.. (LABURU; ARRUDA; NARDI, 2003, p. 252).

Assim, ao considerar a validade de construções lógicas e argumentativas diferentes daquela considerada como cientificamente correta, um professor pode compreender melhor as 
formas de pensamento próprias de seus alunos e, dessa forma, estabelecer um diálogo entre a sua concepção e a dos estudantes. No caso em questão, a concepção a que se refere a presente pesquisa é a manifestada pelo grupo étnico investigado. Explorar a riqueza cultural de suas formas de pensar e de se expressar pode ser uma estratégia profícua na interação com esse grupo social.

É possível, por exemplo, estabelecer relações entre parte e todo, especialmente na forma de expressar as passagem das horas. Nesse aspecto, além da concepção ordinal da leitura das horas, há também a ideia de contagem regressiva para completar a citada hora.

Por exemplo, na leitura do horário "dez horas e vinte minutos", que em sua forma numérica considerada adequada no Sistema Internacional de Unidades de Medida seria grafada como sendo $10 \mathrm{~h} 20 \mathrm{~min}$, um falante do idioma ucraniano expressaria algo como "vinte minutos da décima primeira hora". Nota-se nessa expressão que, após completar a décima hora, o sujeito passa os minutos transcorridos para chegar na próxima hora. Assim, em vez de um critério aditivo de "dez horas, mais vinte minutos", conta-se que "transcorreram vinte minutos da próxima hora", neste caso, a décima primeira.

Contudo, essa forma vale até os trinta minutos da hora. A partir disso, passa-se a contar os minutos que faltam para a próxima hora, seguindo um critério subtrativo semelhante ao utilizado no idioma português. Por exemplo, na leitura do horário 10h40min, o sujeito utiliza a expressão “em vinte minutos será décima primeira hora”.

Além disso, nota-se a utilização de frações, especificamente quarto de hora. A leitura do horário $8 \mathrm{~h} 15 \mathrm{~min}$ seria algo como "um quarto da nona hora". Já 8h45min seria lido como "em um quarto (de hora) será a nona hora".

É possível notar uma estrutura semântica peculiar, algo relacionado com formas tradicionais de leitura de horas e que estão bastante arraigados na cultura desse povo. Embora se observe entre pesquisados uma influência das formas de leitura praticadas pelos brasileiros, há uma preservação da utilização de números ordinais para a leitura de horas, em conjunto com o critério aditivo. Por exemplo, na leitura do horário $18 \mathrm{~h} 50 \mathrm{~min}$, o sujeito 1 e o sujeito 3 utilizaram a forma "décima oitava hora e cinquenta minutos". Já o sujeito 2, empregou a expressão "dez minutos para a décima nona hora”. Em suma, as estruturas utilizadas pelos sujeitos 1 e 3 guardam certa semelhança, e ambas diferem das construções utilizadas pelo sujeito 2.

Se fosse considerado um critério único de adequação, pode-se afirmar que todas as formas de expressão, inclusive aquelas consideradas corretas dentro da norma culta do idioma 
ucraniano estariam excluídas. No entanto, todas as formas são empregadas e, dentro do grupo social a que pertencem, são dotadas de capacidade de transmitir significado, sendo, portanto, socialmente compartilhadas e consideradas válidas.

Cabe, assim, a constatação de que todo conhecimento é válido quando possibilita a comunicação de significados. Dentro do princípio feyerabendiano do "tudo vale", considera-se que a diversidade cultural é uma característica a ser valorizada dentro da sala de aula. Nesse aspecto,

\begin{abstract}
$\mathrm{O}$ argumento pela diversidade procura defender a ideia de que acorrentar as concepções do professor a monolíticos estratagemas, propagados pelos programas pedagógicos, não é produtivo para sua praxe profissional criativa, assim como, limita, ou mesmo fossiliza a sua reflexão crítica, a sua imaginação, frente ao processo de ensino-aprendizagem. Procura defender, ademais, que a tomada de consciência crítica e avaliativa daquele que ensina, frente aos problemas educacionais, evolui na medida em que se supõe um aumento contínuo das suas relações de significado, das suas múltiplas representações, consequência imediata da ampliação e aprofundamento da sua compreensão dos aspectos envolvidos com o lecionar. Esta aptidão é certamente proporcionada pela sua imprescindível insistência, por uma permanente capacitação. Numa proposta pela diversidade, tomamos por válido, então, o princípio heurístico geral que vincula a formação competente do mestre - tanto quanto do aprendiz -, à necessidade de haver uma dependência entre conseguir produzir pessoas com maior sabedoria e o aumento das representações significativamente construídas por essas pessoas. (LABURU et al., 2003, p. 254).
\end{abstract}

De maneira geral, considerar a diversidade cultural, trazê-la para a sala de aula, colocála em discussão partindo do pressuposto de se tratar de conhecimento válido, pode ser uma alternativa interessante para tornar o ensino mais significativo para os estudantes. Ao mesmo tempo, tal estratégia permite ao professor lançar mão de mecanismos para identificar e analisar os obstáculos à aprendizagem de conceitos, em especial de matemática. Há, deste modo, um fortalecimento da dialogicidade, característica de uma prática docente comprometida com a aprendizagem dos estudantes.

\title{
5. Considerações Gerais
}

O propósito deste estudo foi trazer para a discussão uma possível relação entre etnomatemática e pluralismo metodológico. Embora tenha se pautado numa base empírica bastante pontual, entende-se que é possível identificar outros elementos de uma cultura que possam servir como fator de mobilização dos estudantes para a aprendizagem. Para tanto, entende-se que é fundamental adotar uma postura problematizadora. 
Os exemplos apresentados podem ser abordados em comparação às formas usuais, consideradas adequadas, visando estabelecer seu critério de validade no seio da cultura que a originou e buscar a compreensão da concepção de mundo de outros grupos sociais. A estratégia se constitui como uma oportunidade de se buscar o enquadramento de conceitos matemáticos nas construções características de cada povo, permitindo vislumbrar aplicações em diferentes formas de expressão, as quais passam a adquirir significado para o aprendiz, seja ele pertencente ou não ao grupo social produtor do conhecimento em questão.

Assim, entende-se que, durante o processo de ensino, além das diferenças entre a matemática acadêmica e a matemática escolar estabelecidas por Moreira e David (2010), é preciso considerar os aspectos culturais trazidos pelos estudantes, especialmente se eles pertencem a uma comunidade caracterizada por um significativo componente identitário. Dessa forma, considera-se que o potencial de aprendizagem desse grupo social ganha um importante incremento.

\section{Referências}

ALMEIDA, M. C. O nascimento da matemática: a neurofisiologia e a pré-história da matemática. São Paulo: Livraria da Física, 2013.

COSTA, L. T.; LOREGIAN-PENKAL, L. A coleta de dados do banco VARLINFE - variação linguística de fala eslava: peculiaridades e características. Revista Conexão UEPG, v.11, n.1, jan-abr 2015. Disponível em http://www.revistas2.uepg.br/index.php/conexao/article/view/6874/4603, acesso em 03/01/2018.

D'AMBROSIO, U. Etnomatemática: elo entre as tradições e a modernidade. 2. ed. Belo Horizonte: Autêntica, 2002.

FEYERABEND, P. K. Contra o método. Rio de Janeiro: F. Alves, 1977.

FIORENTINI, D. Alguns modos de ver e conceber o ensino da matemática no Brasil. Zetetiké Cempem - FE - Unicamp - ano 3, n. 4, 1995.

HUL, D.; DZIADZIO, S. J.; RIBEIRO DOS SANTOS, C. F. Aplicações matemáticas em medidas agrárias: um conhecimento etnomatemático do homem do campo contextualizado com o conteúdo escolar. In: SIMPÓSIO NACIONAL DE ENSINO DE CIÊNCIA E TECNOLOGIA, 5. Anais... Ponta Grossa (PR), 24 a 26 Novembro 2016. Disponível em http://www.sinect.com.br/2016/down.php?id=3515\&q=1, acesso em 03/01/2018.

JAPIASSU, Hilton F. Introdução ao pensamento epistemológico. Rio de Janeiro: F. Alves, 1934.

KNIJNIK, G. Currículo, etnomatemática e educação popular: um estudo em um assentamento do Movimento Sem Terra. Currículo sem Fronteiras, v.3, n.1, pp.96-110, Jan/Jun 2003. Disponível em http://www.curriculosemfronteiras.org/vol3iss1articles/gelsa.pdf, acesso em 03/01/2018.

LABURU, C. E.; ARRUDA, S. M.; NARDI, R. Pluralismo metodológico no ensino de ciências.

Ciência \& Educação, Bauru, v. 9, n. 2, p. 247-260, 2003. 
LABURU, C. E.; CARVALHO, M. Controvérsias construtivistas e pluralismo metodológico no ensino de ciências naturais. Revista Brasileira de Pesquisa em Ensino de Ciências, Campinas, v. 1, n. 1, p. 57-67, 2001.

MOREIRA, P. C.; DAVID, M. M. M. S. A formação matemática do professor: licenciatura e prática docente escolar. Belo Horizonte: Autêntica, 2010.

REGNER, A. C. K. P. Feyerabend e o pluralismo metodológico. Caderno Catarinense de Ensino de Física, Florianópolis, v. 13, n. 3, p.231-247, dezembro 1996.

ROSA, M.; OREY, D. C. Tendências atuais da etnomatemática como um programa: rumo à ação pedagógica. Zetetiké - Cempem - FE - Unicamp - v.13 - n. 23 - jan./jun. 2005, p.121136.

SILVEIRA, F. L. A metodologia dos programas de pesquisa: a epistemologia de Imre Lakatos.

Caderno Catarinense de Ensino de Física, Florianópolis, v. 13, n. 3, p.219-230, dezembro 1996.

VILELA, D.; MENEGHETTI, R. C. G. Transposição didática ou práticas matemáticas específicas? O caso do número ordinal e cardinal. Educação Matemática Pesquisa, São Paulo, v.13, n.1, pp. 179196, 2011. 